\title{
REGULATION-MAKING: THE CREATIVE OPPORTUNITIES OF THE INEVITABLE
}

\author{
H. W. ARTHURS*
}

The lawmaking process has diffused substantially in the past years, resulting in an increasing maze of departmental subordinate legislation. This phenomenon has not been accompanied by a parallel development of controls resulting in complaints about "bureaucracy", red-tape, inaccessability, and poor draftsmanship, and in demands for review and control. Professor Arthurs recognizes the practical inevitability of the system, but discusses the present situation critically, suggesting reforms which might help to make the regulatory process more compatible with "participatory democracy".

The Special Committee on Statutory Instruments of the Canadian House of Commons was established to consider a universal legislative dilemma: Should parliament itself assume responsibility both for articulating policy and for filling in the details of that policy and directing the manner of its implementation? Or should the cabinet and other administrative intrumentalities be permitted wide lattitude to make "subordinate legislation", subject only to fairly broad policy instructions given by the Legislature?

\section{I}

Let me declare my position at the outset. There ought to be the broadest possible mandate for regulation-making, and parliament ought to confine itself (so far as possible) to the announcement of broad policy lines within which regulations may operate, and to the scrutiny of those regulations. Saying that, I realize that I fly in the teeth of a good deal of the current concern with bureaucracy, with hidden power in government, with all the other sinister influences which are thought to lie athwart the rights of the citizen. I suggest that while in strict theory all law must be made by the legislature, while in strict theory judicial and quasi-judicial bodies merely interpret and apply the law, while in strict theory ministers and other lower-level administrators simply execute instructions given by parliament, it is time to recognize that theory does not, cannot, and indeed should not accord with actual practice.

There are many important reasons why "regulations" or subordinate legislation must be enacted.

1. At the head of the list is the fact that parliamentary time is at a premium and should, therefore, be reserved for doing what parliament does best, namely, debating issues of great public importance at the level of principle and of policy rather than at the level of detail. This type of debate informs the public and attracts and engages its attention more or less in direct proportion to the degree to which it focusses on intelligible issues. The minutiae of administration are not such issues. Thus legislation should be drafted broadly so as to focus parliamentary and public attention on policy, while questions of detail should be left to be filled in afterwards by those best technically equipped to do so.

\footnotetext{
- B.A., LL.B. (1958), LL.M. (1959), Professor and Associate Dean, Osgoode Hall Law School of York University. This note is based upon evidence presented to the Special Committee on Statutory instruments of the House of Commons of Canada (Dr. Mark MacGuigan, M.P., Chairman) on April 22, 1969. The committee's third (and final) report has now been issued (Queen's Printer, Ottawa, 1969).
} 
2. Important legislation may have to be enacted without full knowledge of the social facts of the matters being legislated upon, or of the precise implications of legislation. Some harm to the public interest is sought to be eradicated: the harm may be obvious but not its causes, the causes may be obvious but not the cure-yet the decision has to be taken to deal with the problem. Three alternatives exist in such a situation.

Firstly, it is impossible to assume (without empirical proof) that certain facts exist, on the basis of which detailed legislation can be drafted. If those factual assumptions turn out to be sound, no harm is done. If they should turn out to be unsound, this approach may have created a very serious and dangerous situation in which the legislation might turn out to be entirely inappropriate and unworkable.

Next, in the absence of verifiable factual knowledge, we might go to the other extreme and confer unfettered license upon a minister or administrative agency to decided cases on an ad hoc basis. This approach has the merit of permitting decisions to be made in context. As time goes on the minister or the administrative agency presumably becomes better and better informed and the decisions that are made are more and more responsive to the particular problems coming forward. However, here we encounter a very justifiable concern by those who must comply with these decisions, appear before the tribunal or make submissions to a minister in a particular case: they should know what the rules of the game are so that they can conduct themselves accordingly. Moreover, to deal with important social problems on the basis of a series of ad hoc decisions inevitably leaves substantial areas about which no rule at all has been proclaimed because the problem has not yet been presented for decision.

Because of the risks of these two extremes, we must increasingly resort to the third alternative, the alternative of subordinate legislation, when we are confronted with a situation in which we do not know, and cannot know, what all the facts are until we begin the process of regulation. To authorize the making of subordinate legislation or regulations by some appropriate and knowledgeable person within the broad policy framework established by parliament escapes the excessive rigidity of the first alternative and the excessive vagueness of the second. Yet it does enable the administrator, or the minister, to conduct serious research into altering the rules, with due advanced warning, as it appears that they ought to be altered on the' basis of experience, as more and more facts come to the surface, as they begin more and more obviously to form a pattern.

There is a final practical consideration. No statute can be drafted so carefully and completely as to avoid the necessity for further adumbration, either by a process of ad hoc decisions, or by subordinate legislation. Thus, it is a choice between techniques of extra-parliamentary lawmaking which actually confronts us. Given the realities of parliamentary time pressures, given the difficulty of ascertaining the social facts and of making an intelligent estimate of the kinds of solutions needed for problems which are only half-perceived at the time the decision is made to begin to solve them, recourse to detailed legislation cannot be considered as a workable expedient. 
3. We are increasingly attempting regulation in fields of activity which are of a technical or scientific nature. While parliament is able to specify the general objectives which are to be achieved, it really cannot meaningfully discuss the substantive details of regulation. These details must be worked out on the basis of technical and scientific advice after consultation with experts and must be stated in terms which are intelligible to experts, which use appropriate scientific or technical terminology, and which provide for the participation of experts in the administration of the rules. In this way, the actual quality of rules is likely to be improved both from the public point of view and from the point of view of those who are being regulated.

4. Next, we have those situations where the field of activity being regulated may be-and often must be-of a particularly fluid nature. Here we need to be able to continually revise the substantive rules, often very rapidly in response to shifts in the economy or to new technological or scientific developments. For example, it would be impossible to continually amend legislation to regulate specifically each of the hitherto undreamed-of drugs which continually emerge on the market. In addition, more and more developments in areas of regulated activity take place not merely by reason of scientific innovation, but by reason of a constantly changing perception of the social situation or social values. It must be possible to continually match the rule to meet the problem. This can only be done if someone below the level of parliament itself is able to announce the rule, and to announce it with a fair degree of speed, as well as technical competence.

5. The content of a rule or a regulation may be predicated upon the views of those who are being regulated. It may thus be desirable to adopt a form of law-making which facilitates the expression of these views from time to time. This is participatory democracy at a fairly sophisticated level. for example, if we regulating broadcasting, we should encourage the intelligent expression of views about desirable policy as well as about the problems encountered in particular cases, so that we can intelligently formulate rules. With such participation by those affected, not only will the rules be better, but those people who are governed by them will come to feel that they have a stake in them, will come to feel that they are responsive to the actualities of the industry or the social situation being regulated.

6. Certain details of administrative schemes, particularly those which are of a procedural or a housekeeping nature, may be unworthy of the attention of parliament or sufficiently non-controversial to justify enactment without direct parliamentary intervention or supervision.

7. Finally, and as a broad point, it does seem to me that legislation should be reasonably simple, reasonably easy to read and of a longlasting or permanent character. Each of these qualities is diminished to the extent that more ephemeral matters are dealt with by legislation or to the extent that legislation incorporates a mass of details without any great substantive significance.

For all of these reasons it is highly desirable that substantial opportunity be given to appropriate officials and bodies to make regulations or rules, many of which will have a significant impact on the procedural and substantive rights of citizens. Thus, we should attempt not to 
diminish the scope within which subordinate legislation is permitted to operate. Rather we should seek to ensure that in its operation, and in the process of its enactment, there exist adequate safeguards and opportunities for ultimate debate about policy issues in the public forum, and for full knowledge by those whose conduct is being regulated of the rules to which they are expected to conform.

\section{II}

I now turn to the procedure by which regulations ought to be made. I have already touched on the virtue of providing for participation in the regulation-making process by those who are subjected to the cuttingedge of regulations. To the extent that a statutory order or instrument may be aimed specifically at a particular individual or a particular group, elementary principles of fairness seem to me to demand that an opportunity be given to that individual or group to be heard. This opportunity may be afforded by informal consultation, by an invitation to submit a brief or (alternatively, but not necessarily) by a full-dress public hearing. In some cases, at least, such participation must follow rather than precede the promulgation of an order or a regulation, because of the potential for great damage to the public interest which would occur if the regulation were withheld until the consultative procedures had been exhausted. On the other hand, as a general matter of principle, participation by the governed in the process of government is likely to enhance the effectiveness of the regulatory scheme. And as a corollary, the sudden and unannounced emergence of a regulation affecting the lives or livelihood of individuals and groups is likely to produce in them a feeling of resentment and antagonism, and unwillingness to abide by the policies and practices proclaimed in the regulation.

Neither legislation nor subordinate legislation nor regulations are, in my view, mere collections of words. They are rather the embodiment of value judgments based upon experience and familiarity with the subject matter. I therefore have great reservations about the philosophy that statutory draftsmanship is a pure science. While I immediately concede the need for participation by skilled draftsmen, both as to form and content, I am very anxious that statutory instruments should reflect the milieu in which they are intended to operate. Thus it follows that a predominant influence in the actual drafting of regulations ought to be the department or agency charged with the task of administration. I would add that where members of the public are involved closely and directly with the administration, as for example in the labour relations field and the immigration field, particular care should be taken to frame regulations in non-technical and easily understood language so that the citizen who is faced with the task of coping with those regulations can in fact do something intelligent to secure his own interests. Naturally, a more colloquial approach involves a sacrifice of uniformity.

\section{III}

We must now confront the difficult question of who should make regulations. Obviously, the answer to some degree depends on the type of regulation. Rules relating to procedure or housekeeping, most people 
would agree, can and should be made directly by the department or agency involved. Where a regulations relates to substantive policies, we should move the process of regulation-making to a fairly high level, perhaps to an independent regulatory agency such as the Canada Labour Relations Board or to cabinet itself, depending on where in the particular case responsibility for formulating policy resides. If it is appropriate to keep policy-making within the purview of cabinet, then obviously cabinet must exercise its responsibility for making that policy by announcing it in a regulation. If, on the other hand, it is felt more appropriate to give a fairly broad mandate to an independent and expert agency, then that of course is the appropriate location for the making of the regulation. We should be particularly careful not to thwart the implementation of important public regulartory schemes by forcing the regulation-making function into busy cabinet agenda, especially where no policy issues are involved.

\section{IV}

The review of regulations is clearly a matter of major concern to parliamentarians. Obviously, review may be undertaken for different purposes and therefore requires different procedures. Review, for example, might have as its objective the simple purpose of collection: how can we make sure that we have in hand all regulations relating to a particular subject? Someone who might be termed a "registrar of regulations", someone whose function is essentially a clerical one (but one requiring considerable care and sophistication) could safely be given the job of "review" in this limited sense of ensuring the completeness of a code of regulations. Another example: if we are concerned about review of regulations for the purpose of ensuring their intelligibility, internal consistency or linguistic sophistication, here again we could give the job either to a registrar of regulations or to a branch of the Department of Justice. There are seldom great issues involved in such purely technical scrutiny, which ought to be undertaken before regulations take effect.

If review is intended to ensure that regulations do not offend the Bill of Rights or otherwise unduly infringe upon principles of fairness, this obviously requires a much higher order of supervision. No doubt for this reason, many countries provide for direct review by the legislature or by a legislative committee. The same approach has been prescribed for Canada's parliament. In my submission, however, to simply establish a routine procedure for the tabling of some or all regulations either before the House of Commons or a special "watchdog" committee of the House, does not quite meet the problem.

To be effective, review at this level must, above all, be informed; it must be contextual. A great American administrative law scholar has said that "one man's due process is another's red tape". He was suggesting that one cannot really evaluate the degree to which a particular procedure infringes upon even such a basic policy as due process without seeing it in the lefe context. Consider this illustration: a regulation establishes a time limit of $\mathbf{1 0}$ days for the doing of an act. In the abstract this time limit may seem reasonable, even innocuous. But 10 days, given the particular field of activity, may be as an instant or it may be 
an eternity; one cannot judge without an accurate knowledge of how rapidly events move. What can one really say about a time limit without immersing oneself in the realities of the social or economic events?

It may be also very important to determine whether or not a regulation changes or initiates policy in a particular field or activity. One often cannot tell very much about policy by reading the statute since the operative policy choices are articulated only in the regulations. Here again is an illustration of the prime importance of having informed review: only with a perspective gained from continuous observation of the field of activity over a period of time is it possible to understand the true impact of a regulation.

Which body then, is likely to be most knowledgeable-in a relevant way-about the significance of a regulation? The bodies which are potentially most qualified to perform the reviewing function are the standing committees of the House, concerned with such subject matter areas as agriculture or labour, transportation or broadcasting.

As I envisage it, review would proceed in two ways. First, there ought to be periodic review of legislation and of regulations made under legislation, at least of the major statutes which govern the subject matter areas with which the committees are concerned. Every five years or seven years (or some such reasonable period of time) it should be possible to evaluate the way in which a policy has developed, and to scrutinize in policy terms the regulations made since the last periodic review. I visualize a full-scale look at what has happened, say, in the field of manpower policy or broadcasting policy. As part of that process regulations would necessarily have to be collected and evaluated in the terms of their policy implications.

There is another, and more frequent, opportunity for review. It is expected that the standing committees will acquire considerable familiarity with the subject matter to which they are assigned. Regulations could be routinely circulated to committee members for scrutiny by them as part of the on-going process of educating themselves and of monitoring the particular subject matter within their field of competence. A member of the committee, or some appropriate number of members, could provoke a committee debate on a regulations deemed be of importance by some appropriate procedure.

Needless to say, professional staff must be placed at the disposal of committees charged with this obligation to review, staff who can give very careful scrutiny to the regulations, who can make significant enquiries as to the actual operation of the regulations, and who can record how those regulations affect great constitutional principles or policies embodied in other sources.

The case for review by standing "subject-matter" committees, rather than by a special "watchdog" committee, can be made another way. -There is the risk that a "watchdog" committee would develop a psychological vested interest in its function, a propensity to play the role assigned to it. Tell its members "your role is to ferret out injustices in regulations", and they will ferret out injustices in regulations. Tell them "your role is to develop a coherent and fair system of administering this particular subject matter" and they will tend to focus on that task. Nor is the protection of the public likely to be lessened if it is con- 
signed to "subject-matter" committees. Real unfairness often does not become obvious from a mere reading of the words of a regulation, but only from an assessment of their impact upon the particular area of life being regulated. Likewise, unfairness may sometimes falsely be made to appear if one considers a regulation in the abstract rather than in context.

What if a reviewing committee should decide that a regulation violates some constitutional principle or is for some other reason deemed offensive? If an appropriate committee does formulate the view that there is such a defect in a regulation, it should be permitted to table in the House of Commons a report indicating both its objection to the regulation and the defence of that regulation advanced by those who have made it. This report ought to be regarded as a matter worthy of the attention of the House, and appropriate opportunity afforded for debate. If the House decides to impeach the regulation, this might be accomplished by resolution. Given a reasoned report outlining both the defects and the defense of the regulation, there is some assurance that such a resolution would be the produce of sober consideration.

Because of the infrequency of committee and parliamentary sittings, regulations ought to take effect when they are made, subject to impeachement by the procedure outlined above. A pending regulatory scheme should not have to be kept in a state of suspended animation until the distant date at which a committee can be assembled, especially if the House is not sitting. It must be conceded that if a regulation is made and subsequently impugned, there is some injustice visited upon those who have meanwhile been affected by it. If penalties have been imposed for breach of a regulation which is subsequently overturned, those penalties can usually be remitted. If significant business loss has been suffered, there is cold comfort for those affected by the ultimate vindication of their position.

Yet I really do not see any great risk in such expedient transaction of public business. Few regulations, after all, are lightly promulgated, or likely to be embarked upon entirely without guidlines laid down by Parliament or, for better or worse, immune from judicial impeachment on the grounds of ultra vires.

It is sometimes urged that parliamentary scrutiny is unnecessary because of the general supervisory role of the Department of Justice. While undoubtedly helpful, this is not the answer to all of our problems. The Minister of Justice obviously has his own axe to grind in these matters; he has many other concerns, including the reputation of the government of which he is a member. I therefore do not view his department as the ultimate safeguard in ensuring the appropriateness and fairness of regulations.

Finally, we come to court review. Court review is not a very practical device, and, to the extent that it is, it is largely undesirable. Obviously we cannot prevent a court from finding that regulations do not fall within the scope of a statute. This happens, occasionally, when the court is not sensitive to the nuances of the regulatory scheme or is unsympathetic to the whole purpose of the scheme. From time to time, in such circumstances, courts have by a literal-minded process of in- 
terpretation, seized the occasion to strike down or inhibit some very valuable schemes.

Many times, if one wants to look at it from the other point of view, it is not a question of the court being too eager to intervene, but of there being no real way in which the court's attention can be attracted. Often no one has standing to complain to the court that a particular regulation or a particular policy is offensive, either procedurally or in substantive terms, since no one has a personal grievance, or has suffered an injury which is different from that suffered by the public as a whole. In that sense, if one is intervention-minded the court route does not seem terribly promising.

My lack of enthusiasm for judicial review-and for review by a "watchdog" committee-proceeds from a general scepticism about whether much is to be gained by "putting the fear of God" into administrators. I concede that there are in any administration, whether of the federal government or provincial government (or even the university) people who are so rule-minded, so insensitive to human beings, that they insist on deliberately trampling over people, whether by making regulations or particular decisions; that obviously does happen. However many more injustices are perpetrated by well-intentioned people who simply have not directed their minds to the problem of fair dealing. The solution for those people, who are involved in the great majority of cases, is not to put the fear of God into them. Rather, it is to create an atmosphere in which they see their objective not only as getting from point $A$ to point $B$ in terms of executing policy, but of getting there by a route which is consistent with the values of a democratic society.

How do we do this? Not by scrutiny, whether by court or by committee, after the event. We do it at the beginning of the process. We do it by holding seminars for administrators who are in a position to make this kind of decision; we do it through training, manuals, publications and policy statements, which may or may not have legal force. We do it by creating a consciousness in the minds of the people who are making decisions and making regulations, that they must be sensitive to the basic values of fair dealing. Although many of them are very fine people, they are very busy people and they are never asked (except in a critical sense when they have offended) to pause and consider basic concepts of due process. Let us do something affirmative before the fact, rather than punish them after the fact by embarrassment and chastisement.

Publication and consolidation are our final concerns.

Statutory instruments which bear narrowly on an individual or a small group present no special problem. It is possible to bring a regulation to the attention of that individual or group by personal service upon them. Indeed, this principle is certainly recognized in many statutes which govern the effect of statutory instruments: a person who has personal notice that a regulation has been passed is bound by it.

However, it is indisputable that statutory instruments which have the effect of rules governing the conduct of the public, or a broad sector of the public, should be published, and that they should be freely avail- 
able for inspection at the time and place at which they are being applied. Customs and immigration are two notorious areas in which regulations are often not freely available at an appropriate time and place to those who are being subjected to them.

In this connection, to repeat a point already made, regulations should be intelligible to the persons affected by them. The pure science of drafting, so prized in some circles, ought to give way to intelligibility. There is no more important principle than intelligibilty when laws affect layment. And there is no more important principle in aid of intelligibility, besides the actual selection of words, than the consolidation of words, the review of random regulations made from time to time, and their republication in some coherent and collected form.

There are many solutions to this problem which have been adopted by private publishers, some of which are occasionally resorted to by governments. There is the obvious expedient of periodic consolidation. How periodically things are consolidated, or ought to be consolidated, is perhaps a matter of debate. I, for example, do not consider consolidation of the 1952 Revised Statutes of Canada at some date subsequent to 1969 as being quite periodic enough for my taste, but I can see that tastes may differ in this regard. That is the classic method of bringing together regulations and legislation. There are more up-to-date methods such as the loose leaf services offered by the many private law publishers and people in other lines of endeavour, who meet the recurring need to keep a body of material both current and consolidated. I see no reason why such expedients could not be used.

There is, of course, the wave of the future: computerized retrieval. I envisage ultimately a situation in which there are a number of local routes into a central federal legislative computer bank which contains all statutes and regulations administered by the various departments and agencies of government. Someone administering those rules in Toronto or Vancouver or Quebec City or Halifax, should, by means of a fairly simple dialogue with this device, be able to obtain a definitive answer to the question, "What rules govern the situation?" The opportunity to ask the question and obtain the answer should be equally accessible to the citizen. I cannot think of anything more likely to give rise to genuine concern about the process of regulation-making within government than denial to citizens of free and full access to the rules that are made. 